\title{
FOSFITOS NO CONTROLE IN VITRO DE Sclerotinia sclerotiorum e Sclerotium rolfsii
}

Renata Silva Canuto de Pinho ${ }^{1}$, Thaís Trindade Viçosa ${ }^{2}$, Bruna Canabarro Pozzebon ${ }^{3}$, Ketlen Raisa Rey Rodrigues ${ }^{4}$, Mireli Duarte Bergmann ${ }^{5}$.

${ }^{1}$ Professora Doutora, Universidade Federal do Pampa/Campus Itaqui, (renatapinho@unipampa.edu.br).

${ }^{2}$ Discente do curso de Agronomia, Universidade Federal do Pampa/Campus Itaqui.

${ }^{3}$ Pesquisadora Visitante, Universidade Federal do Pampa/Campus Itaqui.

${ }^{4}$ Discente do curso de Agronomia, Universidade Federal do Pampa/Campus Itaqui.

${ }^{5}$ Discente do curso de Agronomia, Universidade Federal do Pampa/Campus Itaqui.

\section{Recebido em: 06/04/2019 - Aprovado em: 10/06/2019 - Publicado em: 30/06/2019 DOI: 10.18677/EnciBio_2019A72}

\begin{abstract}
RESUMO
Dentre os fatores limitantes para o aumento do potencial produtivo da soja, estão as doenças causadas por patógenos fúngicos, como o mofo branco (Sclerotinia sclerotioum) e a murcha de esclerócio (Sclerotium rolfsii). Dessa forma, objetivou-se com esse estudo, avaliar o potencial de fosfitos de cobre, zinco e potássio, no controle in vitro de Sclerotinia sclerotiorum e Sclerotium rolfsii. Para isso, avaliou-se o efeito de fosfitos no índice de velocidade de crescimento micelial (IVCM), na produção de escleródios, e o efeito de doses do fosfito de zinco, no índice de velocidade de crescimento micelial dos dois patógenos. Os dados obtidos mostraram que o tratamento com fosfito de zinco reduziu o crescimento micelial de $S$. sclerotiorum e S. rolfsii em 95 e 93\%, respectivamente, quando comparados com a testemunha $(100 \%$ de crescimento micelial). Com relação a produção de escleródios, o fosfito de zinco e o fosfito de potássio (A) reduziram em $93 \%$ a produção de escleródios de $S$. rolfsii. Contudo, para $S$. sclerotiorum, não foi possível realizar essa avaliação, pois o patógeno não produziu escleródios durante o período avaliado. Ao avaliar-se o efeito de doses de fosfito de zinco, escolhido por ser o mais eficaz no teste de redução do crescimento micelial, observou-se que a dose $8 \mathrm{~mL} . \mathrm{L}^{-1}$ foi a mais eficaz para os dois patógenos. Dessa forma, pode-se concluir que a suplementação do meio de cultura com fosfito de zinco é eficaz no controle in vitro de Sclerotinia sclerotiorum e Sclerotium rolfsii.
\end{abstract}

PALAVRAS-CHAVE: crescimento micelial, mofo branco, murcha de esclerócio.

\section{PHOSPHITES IN CONTROL IN VITRO Sclerotium rolfsii and Sclerotinia sclerotiorum}

\section{ABSTRACT}

Among the limiting factors to increase soybean production potential are diseases caused by fungal pathogens such as white mold (Sclerotinia sclerotioum) and sclerotium rolfsii (Sclerotium rolfsii). The objective of this study was to evaluate the potential of copper, zinc and potassium phosphites in the in vitro control of Sclerotinia 
sclerotiorum and Sclerotium rolfsii. For this, the effect of phosphites on the rate of mycelial growth rate (IVCM), on the production of sclerotia, and the effect of doses of zinc phosphite on the rate of mycelial growth of the two pathogens were evaluated. The data obtained showed that zinc phosphite treatment reduced mycelial growth of S. sclerotiorum and S. rolfsii in 95 and $93 \%$, respectively, when compared to the control (100\% mycelial growth). With regard to the production of sclerotia, zinc phosphite and potassium phosphite $(\mathrm{A})$ reduced the sclerotia production of $S$. rolfsii by $93 \%$. However, for $S$. sclerotiorum, it was not possible to carry out this evaluation, since the pathogen did not produce sclerotia during the period evaluated. When evaluating the effect of doses of zinc phosphite, chosen for being the most effective in the test of reduction of mycelial growth, it was observed that the $8 \mathrm{~mL} . \mathrm{L}^{-1}$ dose was the most effective for the two pathogens. Thus, it can be concluded that supplementation of the culture medium with zinc phosphite is effective in the in vitro control of Sclerotinia sclerotiorum and Sclerotium rolfsii.

KEYWORDS: mycelial growth, white mold, wilt of sclerotia.

\section{INTRODUÇÃO}

A soja foi a cultura de interesse econômico que apresentou maior crescimento nas últimas três décadas no Brasil, ocupando atualmente, em torno de $49 \%$ da área plantada com grãos no país, apresentando produção na safra 2017/2018 de 118,9 milhões de toneladas (CONAB, 2018). Porém, entre os fatores limitantes e que causam reduções do desenvolvimento máximo do potencial produtivo dessa cultura, nas diversas regiões brasileiras, em que é cultivada, destacam-se doenças de etiologia fúngica.

Conhecidos como patógenos de solo, os fungos Sclerotinia sclerotiorum e Sclerotium rolfsii, agentes causais do mofo branco e murcha de esclerócio, respectivamente, podem diminuir o potencial produtivo e acarretar decréscimos de produtividade, quando ocorrem em condições favoráveis ao desenvolvimento do patógeno, e solos muitos infectados com esses patógenos, podem comprometer cultivos futuros (MARCUZZO; SCHULLER, 2014; SUMIDA et al., 2015).

O mofo branco, por exemplo, se manifesta em qualquer parte da planta, começando, geralmente, pelas partes mais próximas do solo, na forma de manchas de anasarca, que evoluem para coloração castanho-clara, com abundante formação de micélio cotonoso de coloração branca, que em poucos dias evolui para a formação de escleródios (GODOY et al., 2016). Já a murcha de esclerócio pode ocorrer tanto no colo como na parte aérea da planta, que se torna verde-clara, começa a murchar e seca. Além disso, nos pontos de infecção, o patógeno $S$. rolfsii também produz micélio cotonoso abundante e forma escleródios na parte externa da planta (GODOY et al., 2016). Além disso, depois de introduzidos na lavoura, o manejo desses patógenos torna-se difícil, devido à produção constante de escleródios, estruturas de resistência e disseminação desses fungos, que permanecem viáveis por vários anos, e dificilmente são atingidas por fungicidas (JULIATTI et al., 2015).

Contudo, apesar de métodos como rotação de culturas, manutenção de cobertura morta no solo e principalmente a aplicação constante de fungicidas apresentar bons resultados no manejo desses patógenos, a preocupação da sociedade com o impacto da agricultura no ambiente e a contaminação da cadeia alimentar com os agroquímicos, vem alterando o cenário agrícola atual (ZAMBOLIM et al., 2014), que busca por fontes mais seguras para integração aos métodos de controle já existentes, de forma mais eficiente. Portanto é necessário aumentar 
estudos e recursos dedicados a métodos de controle alternativos, que atuem de forma mais sustentável no manejo de doenças de plantas. Nesse contexto, o uso de fosfitos pode ser uma alternativa eficaz.

Registrados como fertilizantes foliares, os fosfitos têm apresentado crescimento progressivo nas atuais práticas agrícolas, pois o mecanismo de ação desses produtos atua ativando mecanismos de defesa da planta e na inativação de enzimas interligadas com a patogenicidade, tendo, dessa forma, efeito direto sobre o patógeno, e indireto na indução de resistência sistêmica da planta, além de apresentarem taxas nulas de poluição e toxicidade ao meio ambiente (BRUZAMARELLO et al., 2018). Dessa forma, objetivou-se com esse estudo, avaliar o potencial de fosfitos de cobre, zinco e potássio, no controle in vitro de Sclerotinia sclerotiorum e Sclerotium rolfsii.

\section{MATERIAL E MÉTODOS}

Os experimentos foram realizados no Laboratório de Fitopatologia e Microbiologia do Solo da Universidade Federal do Pampa - UNIPAMPA/Campus Itaqui. Os isolados de Sclerotinia sclerotiorum e Sclerotium rolfsii foram oriundos da Micoteca do Laboratório de Fitopatologia e Microbiologia do Solo da UNIPAMPA Campus Itaqui.

\section{Efeito de fosfitos de cobre, zinco e potássio no crescimento micelial de Sclerotinia sclerotiorum e Sclerotium rolfsii}

Para esse ensaio, foram utilizados os fosfitos de cobre $(\mathrm{Cu})$, zinco $(\mathrm{Zn})$ e potássio (K) (Tabela 1). Para isso, cada fosfito foi incorporado ao meio de cultura Batata-Dextrose-Ágar (BDA) fundente $\left(45-50^{\circ} \mathrm{C}\right)$, fórmula comercial $\left(39 \mathrm{~g} . \mathrm{L}^{-1}\right)$, previamente autoclavados e acrescido de antibiótico cloranfenicol $(10 \mathrm{mg} / \mathrm{mL})$, nas concentrações recomendadas pelos respectivos fabricantes. Como testemunha, utilizou-se apenas o meio de cultura BDA, sem adição dos fosfitos.

TABELA 1 - Tratamentos utilizados nos testes in vitro contra os patógenos fúngicos Sclerotinia sclerotiorum e Sclerotium rolfsii.

\begin{tabular}{ccc}
\hline Tratamentos & Composição & Concentração (mL.L-1) \\
\hline Fosfito de $\mathrm{K}+\mathrm{Cu}$ & $4 \%$ de $\mathrm{Cu}, 20,3 \%$ de $\mathrm{P}_{2} \mathrm{O}_{5}$ & 5,0 \\
Fosfito de $\mathrm{Zn}$ & $10 \%$ de $\mathrm{Zn}, 34 \%$ de $\mathrm{P}_{2} \mathrm{O}_{5}$ & 3,0 \\
Fosfito de $\mathrm{K}(\mathrm{A})$ & $19 \%$ de $\mathrm{K}_{2} \mathrm{O}, 26 \%$ de $\mathrm{P}_{2} \mathrm{O}_{4}$ & 3,0 \\
Fosfito de $\mathrm{K}(\mathrm{B})$ & $26 \%$ de $\mathrm{K}_{2} \mathrm{O}, 33,6 \%$ de & 3,0 \\
& $\mathrm{P}_{2} \mathrm{O}_{4}$ \\
Fosfito de $\mathrm{Cu}$ & $20 \%$ de $\mathrm{P}_{2} \mathrm{O}_{5}, 1,75 \%$ de S, & 5,0 \\
& $3,5 \% \mathrm{Cu}$ & - \\
Testemunha (sem aplicação) & - & - \\
\hline
\end{tabular}

Posteriormente, foram transferidos para o centro de cada placa de Petri contendo meio de cultura suplementado com fosfito, discos de cinco $\mathrm{mm}$ de diâmetro, contendo micélio dos patógenos. Após a repicagem dos fungos, as placas foram incubadas em câmara de crescimento (BOD), a temperatura de $25{ }^{\circ} \mathrm{C}$ e fotoperíodo de $12 \mathrm{~h}$.

O crescimento micelial dos fungos foi avaliado em intervalos de $24 \mathrm{~h}$, em que o diâmetro da colônia foi mensurado em centímetros com uma régua, na posição vertical e horizontal. As medições foram interrompidas quando o crescimento micelial atingiu a borda da placa, o que ocorreu, após quatro dias de incubação. 
Foi calculado o Índice de Velocidade de Crescimento Micelial (IVCM) dos fungos, a partir dos dados dos diâmetros das colônias (MAIA et al., 2011) (ANEXO 1). Os ensaios foram conduzidos em delineamento experimental inteiramente casualizado (DIC), composto de seis tratamentos (cinco fosfitos e uma testemunha) e cinco repetições para cada tratamento, sendo a unidade experimental constituída por uma placa de Petri.

\section{Efeito dos fosfitos sobre a produção de escleródios de Sclerotium rolfsii}

Para avaliar o efeito dos fosfitos na inibição da produção de escleródios de $S$. rolfsii, o patógeno foi transferido para meio de cultura suplementado com os fosfitos, e após 15 dias de incubação em câmara de crescimento tipo BOD, à temperatura de $25 \stackrel{\circ}{\circ}$ e fotoperíodo de $12 \mathrm{~h}$ avaliou-se a produção de escleródios de $S$. rolfsii por placa. Não foi possível avaliar a produção de escleródios de $S$. sclerotiorum, pois não ocorreu a produção do mesmo em meio de cultura.

\section{Efeito de doses de fosfito de zinco no crescimento micelial de Sclerotinia sclerotiorum e Sclerotium rolfsii}

Para avaliar o efeito de doses contra o crescimento micelial de $S$. sclerotiorum e S. rolfsii, selecionou-se o fosfito de zinco, que apresentou o maior efeito de inibição no crescimento micelial dos dois patógenos. Esse teste constou da avaliação específica da eficiência do fosfito de zinco na inibição do crescimento micelial dos dois fungos através da suplementação do meio de cultura em diferentes doses do produto.

Para isso, o meio de cultura BDA foi suplementado com fosfito de zinco nas seguintes concentrações: 0 (testemunha), 2, 4, 6 e $8 \mathrm{~mL} . \mathrm{L}^{-1}$. Posteriormente, repicou-se no centro da placa de Petri contendo meio de cultura suplementado, discos de cinco $\mathrm{mm}$ de micélio de $S$. sclerotiorum e $S$. rolfsii, e incubou-se as mesmas em câmara de crescimento tipo $\mathrm{BOD}$, a $25^{\circ} \mathrm{C}$, durante quatro dias - período necessário para que o crescimento micelial da testemunha atingisse a borda da placa. As avaliações foram realizadas em intervalos de $24 \mathrm{~h}$, mensurando-se 0 diâmetro da colônia dos patógenos $\mathrm{em} \mathrm{cm}$ com régua na posição vertical e horizontal.

O delineamento experimental foi inteiramente casualizado (DIC), com cinco tratamentos e cinco repetições para cada fungo, sendo a unidade experimental composta por uma placa de Petri.

\section{Análises Estatísticas}

Os dados obtidos foram analisados estatisticamente no software SISVAR, versão 5.6 (FERREIRA, 2011), em que os valores de IVCM foram submetidos às análises de variância, e as médias, quando significativas, analisadas pelo teste de Tukey $(p \leq 0.05)$. No teste de doses de fosfito de zinco, os dados foram submetidos à análise de regressão.

\section{RESULTADOS E DISCUSSÃO}

Dos cinco fosfitos testados, o tratamento com fosfito de zinco obteve o menor IVCM de S. sclerotiorum, reduzindo o crescimento micelial em 95\%, quando comparado com a testemunha (100\% de crescimento micelial) (Tabela 2; Figura 1). Já os tratamentos com fosfito de potássio + cobre e fosfito de cobre reduziram em 60 e $58 \%$, respectivamente, o IVCM de S. sclerotiorum, quando comparados com a testemunha (Tabela 2). Já os tratamentos com os dois fosfitos de potássio 
apresentaram potencial de redução do IVCM inferiores a 50\%, sendo, dessa forma, considerados insatisfatórios no controle do patógeno (Tabela 2).

Com relação ao IVCM de $S$. rolfsii, o tratamento mais eficaz na redução do crescimento micelial do patógeno também foi o fosfito de zinco, apresentando redução de $93 \%$ do crescimento de $S$. rolfsii (Tabela 2; Figura 2). Contudo, à exceção do fosfito de zinco, nenhum dos demais tratamentos apresentou redução do crescimento micelial do patógeno acima de 50\% (Tabela 2).

TABELA 2 - Efeito de fosfitos no Índice de Velocidade de Crescimento Micelial (IVCM) de Sclerotinia sclerotiorum e Sclerotium rolfsii.

\begin{tabular}{ccc}
\hline Tratamentos & IVCM S. sclerotiorum & IVCM S. rolfsii \\
\hline Fosfito de Zn & $0,12 \mathrm{a}^{*}$ & $0,16 \mathrm{a}^{*}$ \\
Fosfito de K + Cu & $1,06 \mathrm{~b}$ & $1,46 \mathrm{~b}$ \\
Fosfito de Cu & $1,12 \mathrm{~b}$ & $1,92 \mathrm{c} \mathrm{d}$ \\
Fosfito de K (A) & $2,13 \mathrm{c}$ & $1,59 \mathrm{~b} \mathrm{c}$ \\
Fosfito de K (B) & $2,52 \mathrm{~d}$ & $1,97 \mathrm{~d} \mathrm{e}$ \\
Testemunha & $2,62 \mathrm{~d}$ & $2,33 \mathrm{e}$ \\
\hline CV (\%) & 10,53 & 11,81 \\
\hline
\end{tabular}

*Médias seguidas pelas mesmas letras não diferem entre si pelo teste de Tukey ( $p \leq$ 0.05).

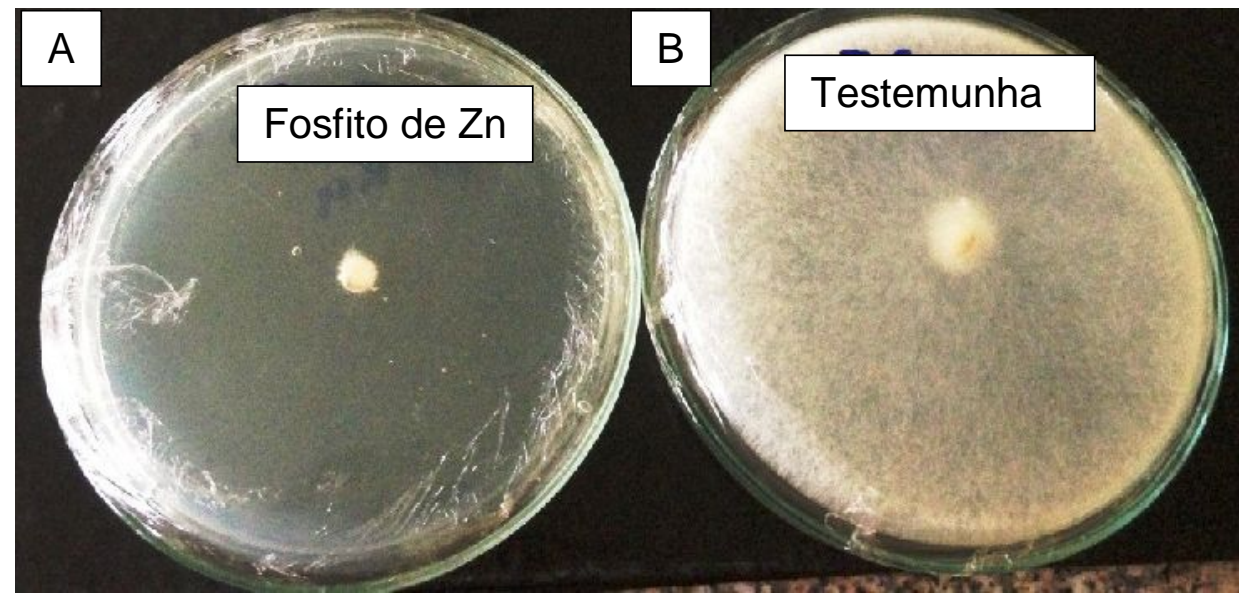

FIGURA 1 - Crescimento micelial de Sclerotinia sclerotiorum em meio suplementado com fosfito de zinco (A); crescimento micelial de Sclerotinia sclerotiorum em meio sem suplementação com fosfito (testemunha) (B). Fonte: VIÇOSA, 2015.

Os resultados do presente estudo estão de acordo com os obtidos por Dambros et al. (2016), que avaliaram a eficácia de cinco fosfitos na inibição do crescimento micelial de Aspergillus niger em uva de mesa. Os resultados obtidos por esses autores demonstraram que todos os fosfitos inibiram o crescimento micelial do patógeno, porém o fosfito de zinco foi o mais eficaz. Além disso, Lucero et al. (2014), ao verificarem a atividade fungistática desse sal na inibição do crescimento micelial 
de Phytophthora nicotinae, observaram que o fosfito de zinco inibiu completamente o crescimento do patógeno.

Todavia, ao verificar o efeito dos dois fosfitos de potássio (A e B), verificou-se que os mesmos não apresentaram resultados satisfatórios para esse estudo. De acordo com Caixeta et al. (2012), a ação fungistática do fosfito de potássio depende do fungo testado. Neste trabalho nenhuma das doses testadas de fosfito de potássio foi eficiente para o controle micelial do fungo $S$. sclerotiorum. Os resultados obtidos por esses autores suportam os obtidos nesse estudo, em que os fosfitos de potássio praticamente não diferiram da testemunha.

Também foi possível observar nesse estudo que todos os fosfitos apresentaram diferentes efeitos sobre o patógeno, interferindo em maior ou menor nível o desenvolvimento micelial do fungo. Tais efeitos, podem estar relacionados ao fato de cada formulação apresentar $\mathrm{pH}$ diferente, e pelo fato de não ter sido feita a correção do $\mathrm{pH}$ do meio de acordo com a faixa de $\mathrm{pH}$ de desenvolvimento do fungo.

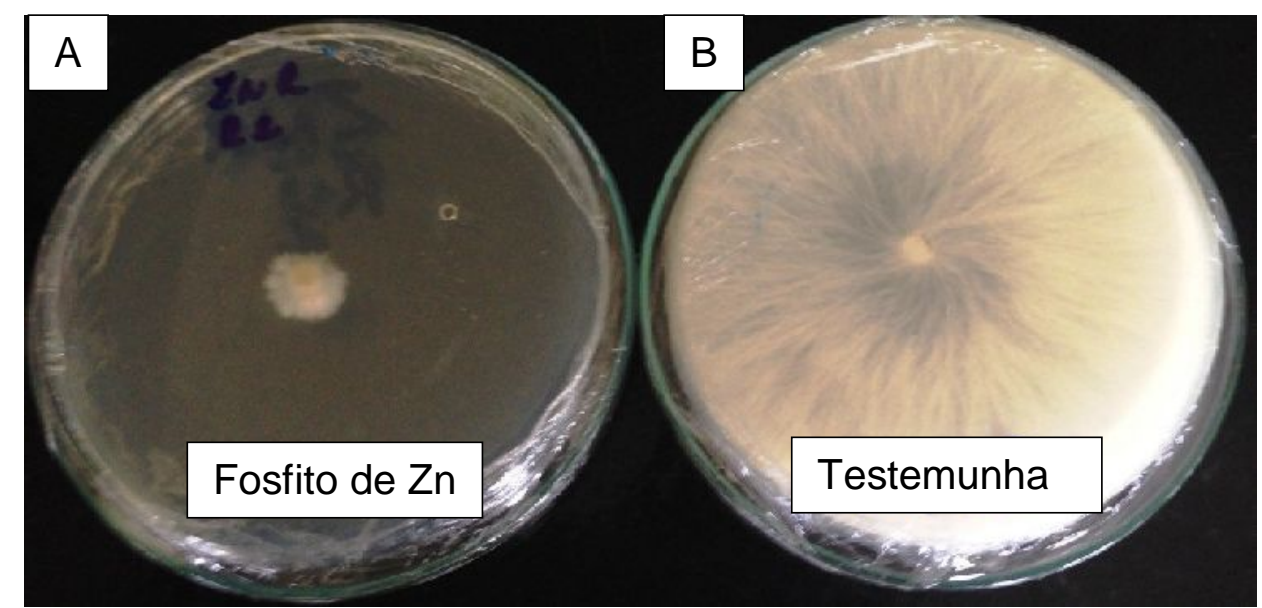

FIGURA 2 - Crescimento micelial de Sclerotium rolfsii em meio suplementado com fosfito de zinco (A); crescimento micelial de Sclerotium rolfsii em meio sem suplementação com fosfito (testemunha) (B). Fonte: VIÇOSA, 2015.

Quando avaliou-se a produção de escleródios dos patógenos mediante a suplementação do meio de cultura com os fosfitos, observou-se que o fosfito de zinco e o fosfito de potássio $(A)$ foram os mais eficazes, reduzindo em $93 \%$ a produção de escleródios de $S$. rolfsii (Tabela 3). Com relação à $S$. sclerotiorum, não foi possível realizar essa avaliação, pois o patógeno não produziu escleródios no período avaliado.

TABELA 3 - Efeito dos fosfitos na produção de escleródios de Sclerotium rolfsii.

\begin{tabular}{cc}
\hline Tratamentos & Número de escleródios \\
\hline Fosfito de $\mathrm{Zn}$ & $0,70 \mathrm{a}^{*}$ \\
Fosfito de $\mathrm{K}(\mathrm{A})$ & $0,70 \mathrm{a}$ \\
Fosfito de $\mathrm{K}+\mathrm{Cu}$ & $3,55 \mathrm{a} \mathrm{b}$ \\
Fosfito de K (B) & $6,44 \mathrm{~b} \mathrm{c}$ \\
Fosfito de $\mathrm{Cu}$ & $8,59 \mathrm{c}$
\end{tabular}




CV (\%) 39,76

${ }^{\star}$ Médias seguidas pelas mesmas letras não diferem entre si pelo teste de Tukey ( $p \leq$ 0.05).

Provavelmente a presença dos tratamentos fosfito de zinco e fosfito de potássio, no meio de cultura, interferiram na absorção de nutrientes pelo fungo, o que acarretaria o menor desenvolvimento de escleródios, haja vista que, para que ocorra o desenvolvimento dessas estruturas é necessário que o meio de cultura sejam ricos em nutrientes básicos, como fósforo e potássio, bem como fontes de carbono ricas em açúcares e ácidos orgânicos (GARCIA et al., 2012).

Ao avaliar o efeito de doses de fosfito de zinco, escolhido por ser o mais eficaz no teste de redução do crescimento micelial para os dois patógenos, foi possível verificar que o crescimento micelial de $S$. sclerotiorum é inversamente proporcional a maior dose, ou seja, quanto maior a dose, menor será o crescimento.

Dessa forma, a dose de $8 \mathrm{~mL} . \mathrm{L}^{-1}$ propiciou uma redução do crescimento desse patógeno de quase $95 \%$, enquanto que na menor dose $\left(2 \mathrm{~mL} \cdot \mathrm{L}^{-1}\right)$, a redução do crescimento micelial atingiu apenas $23 \%$ (Figuras 3 e 4). Entretanto, segundo Ávila et al. (2012), deve-se ter cuidado com o uso de altas doses de fosfito, pois em condições de baixa disponibilidade de fósforo no solo, doses mais altas podem ser tóxicas para as plantas.

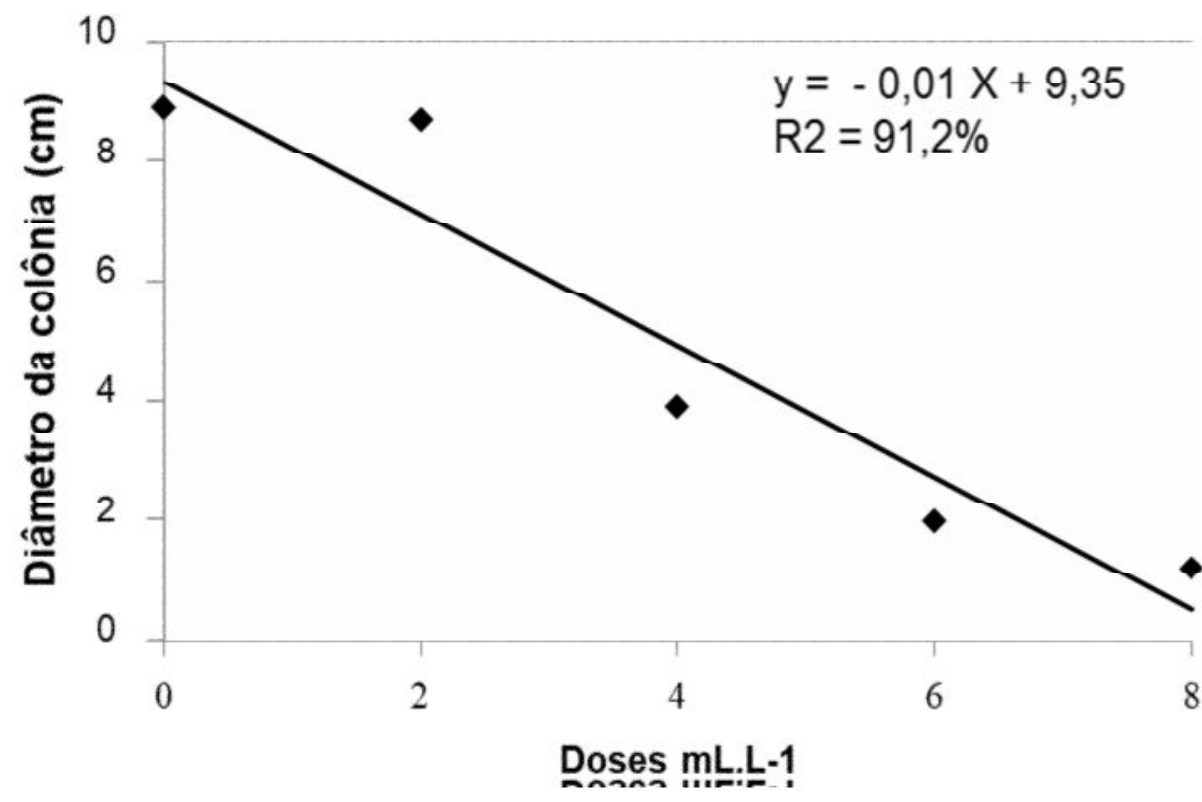

FIGURA 3 - Efeito das diferentes doses de fosfito de zinco no crescimento micelial de Sclerotinia sclerotiorum. 


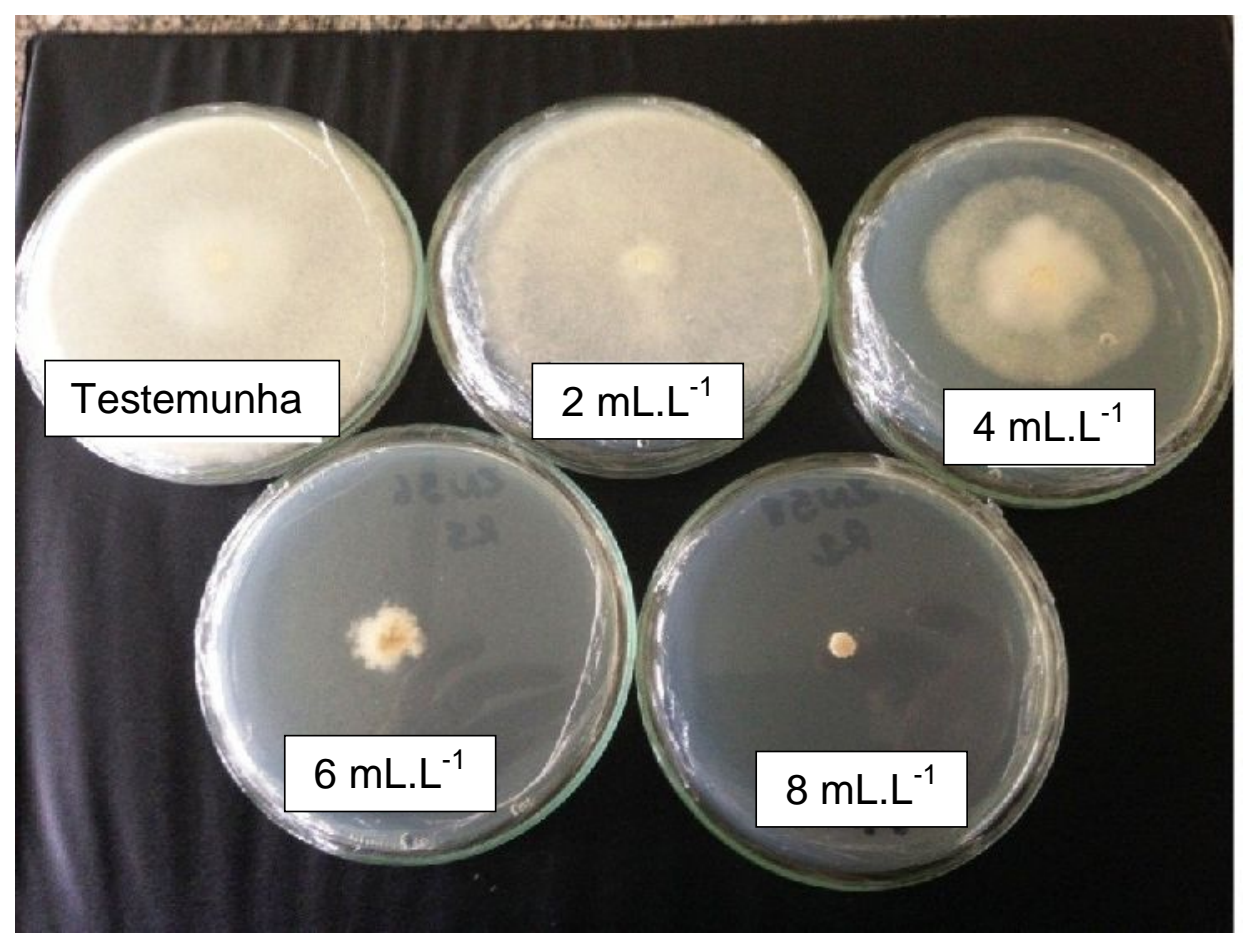

FIGURA 4 - Crescimento micelial de Sclerotinia sclerotiorum em meio de cultura BDA, suplementado com diferentes doses de fosfito de zinco. Fonte: VIÇOSA, 2015.

Já para $S$. rolfsii, os resultados obtidos mostraram que, apesar de todas as doses serem eficazes no controle do desenvolvimento do fungo, a partir da dose de $4 \mathrm{~mL} . \mathrm{L}^{-1}$ de fosfito de zinco, começa a ocorrer uma redução significativa do crescimento micelial do patógeno (em torno de $65 \%$ de redução), em relação a testemunha (100\% de crescimento). Nesse caso também, a melhor dose foi a de 8 $\mathrm{mL} . \mathrm{L}^{-1}$, inibindo em torno de $90 \%$ o crescimento micelial do patógeno em questão. Para todas as doses testadas, nenhuma apresentou produção de escleródios, mesmo após 15 dias mantidos em câmara de crescimento (BOD) (Figuras 5 e 6).

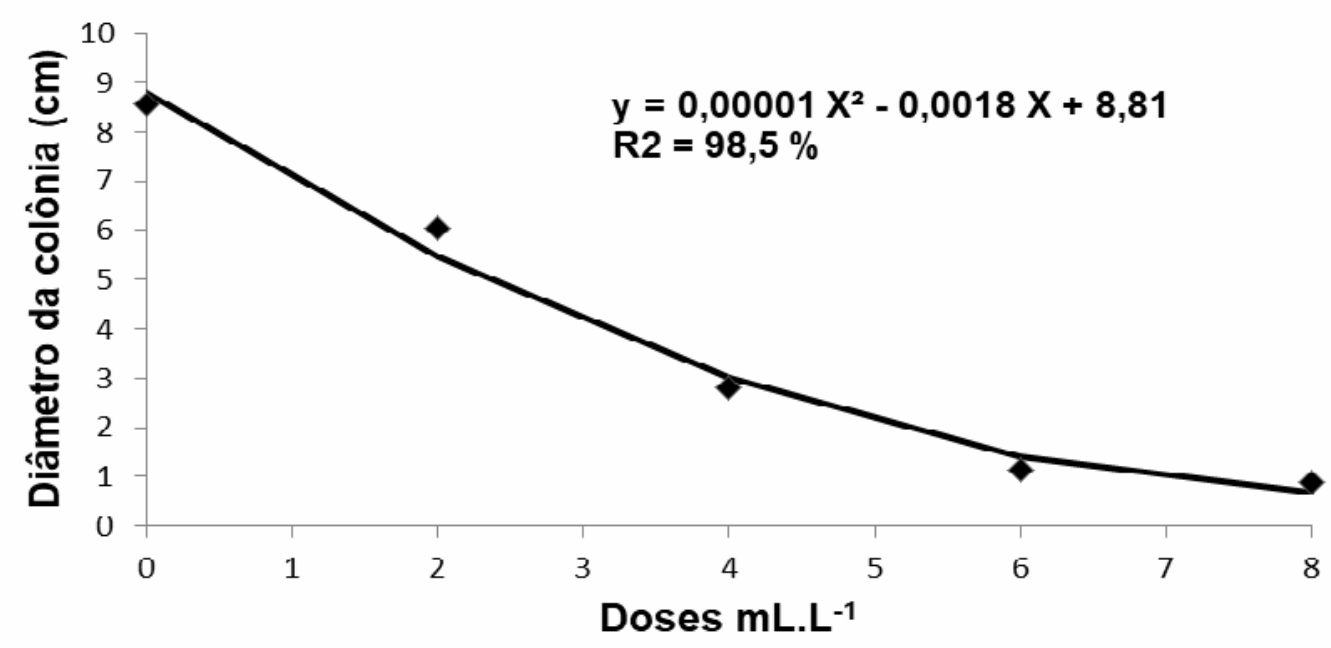

FIGURA 5 - Efeito das diferentes doses de fosfito de zinco no crescimento micelial de Sclerotium rolfsii. 


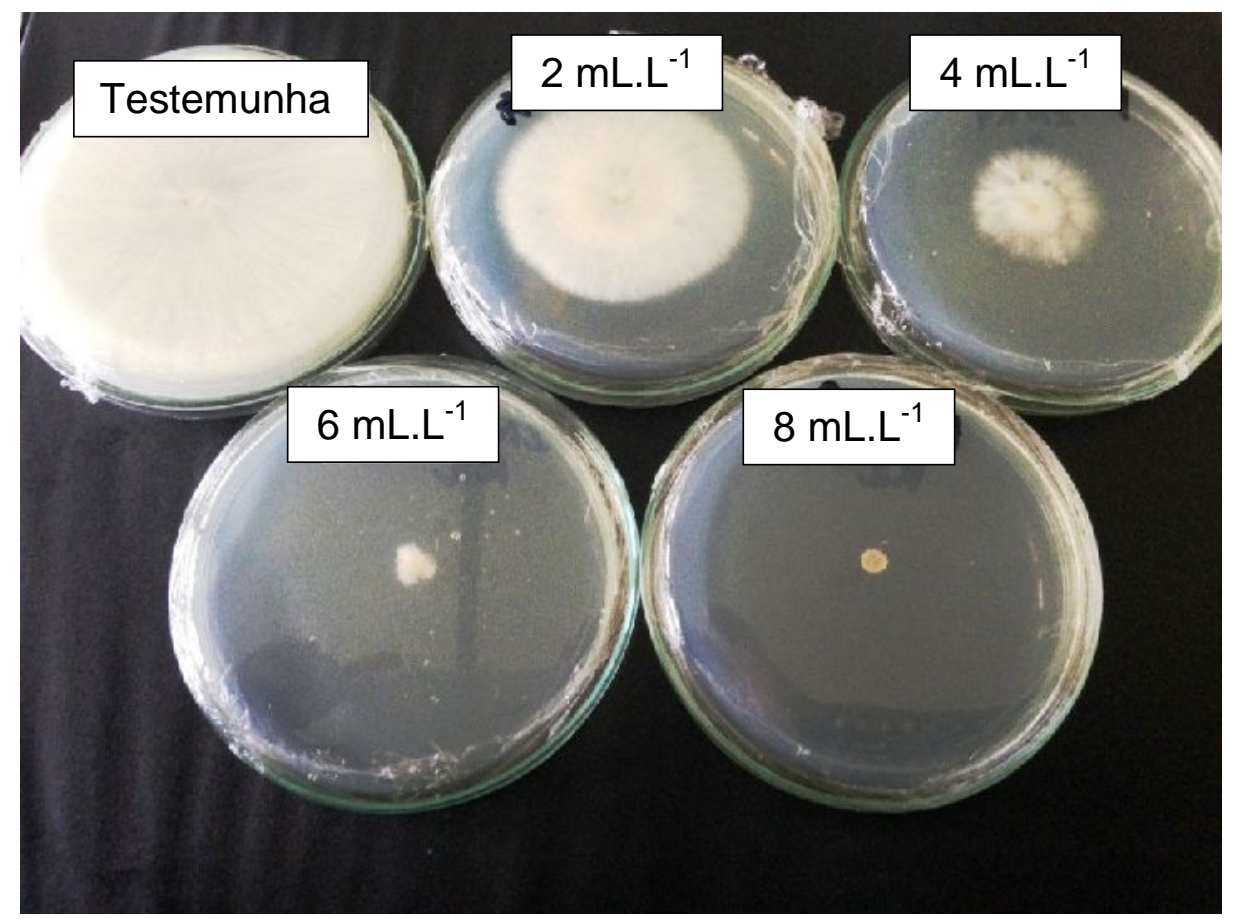

FIGURA 6 - Crescimento micelial de Sclerotium rolfsii em meio de cultura BDA, suplementado com diferentes doses de fosfito de zinco. Fonte: VIÇOSA, 2015.

De acordo com Araújo et al. (2010), a concentração de fosfito pode afetar o $\mathrm{pH}$ do meio de cultura. Dessa forma, em suas avaliações, observou que dosagens de $1,5 \mu \mathrm{L} / \mathrm{mL}^{-1}$ resultaram em $\mathrm{pH}$ mais baixo, próximo de 3,0 , e dosagens maiores como $3,0 \mu \mathrm{L} / \mathrm{mL}^{-1}$, aumentaram o $\mathrm{pH}$ do meio para 6,8. A maior parte dos fungos tolera diferentes faixas de $\mathrm{pH}$, mas o seu desenvolvimento é baseado nos limites de máximo e mínimo, ou seja, quando o pH está abaixo do limite, o fungo tem seu desenvolvimento prejudicado, e acima do limite, o fungo tem o máximo de seu crescimento.

Levando em conta o $\mathrm{pH}$ resultante das dosagens citadas pelo autor acima, é possível justificar os resultados avaliados no presente trabalho, pois, sabe-se que o patógeno $S$. rolfsii apresenta uma faixa de $\mathrm{pH}$ ótimo para o crescimento micelial que varia de 3,0 a 5,0, e apenas quando o pH fica acima de 7,0 a germinação é inibida. Isso justificaria o motivo de as dosagens mais baixas de fosfito de zinco propiciarem um melhor desenvolvimento da colônia do patógeno, quando comparado com as dosagens maiores, que inibiram quase $100 \%$ do desenvolvimento micelial de $S$. rolfsii.

\section{CONCLUSÃO}

Dos cinco fosfitos testados, o fosfito de zinco foi o mais eficiente na redução do crescimento micelial in vitro de Sclerotinia sclerotiorum e Sclerotium rolfsii. Além disso, quando foi avaliado o efeito de doses desse tratamento, a suplementação do meio de cultura com $8 \mathrm{~mL} . \mathrm{L}^{-1}$ de fosfito de zinco foi altamente eficaz no controle dos dois patógenos. Contudo, pesquisas em níveis de casa de vegetação e campo ainda são necessárias e serão desenvolvidas, visando elucidar melhor os fenômenos envolvidos no controle dos dois patógenos. 


\section{REFERÊNCIAS}

ARAÚJO, L.; VALDEBENITO-SANHUEZA, R. M.; STADNIK, M. J. Avaliação de formulações de fosfito de potássio sobre Colletotrichum gloeosporioides in vitro e no controle pós-infeccional da mancha foliar de Glomerella em macieira. Tropical Plant Pathology, v.35, n.1, p.54-59, 2010. Disponível em: <http://www.scielo.br/pdf/tpp/v35n1/a10v35n1>. doi: 10.1590/S198256762010000100010.

ÁVILA, F. W.; FAQUIN, V.; DA SILVA LOBATO, A. K.; BALIZA, D. P.; MARQUES, D. $J$. et al. Growth, phosphorus status, and nutritional aspect in common bean exposed to different soil phosphate levels and foliar-applied phosphorus forms. Scientific Research and Essays, v.7, n.25, p.2195-2204, 2012. Disponível em: <https://ainfo.cnptia.embrapa.br/digital/bitstream/item/63765/1/Avila-et-al-1.pdf>. doi: 10.5897/SRE11.1329.

BRUZAMARELLO, J.; FRANCESCHI, V. T.; DALACOSTA, N. L.; GONÇALVES, I.; MAZARO, S. M.; REIS, E. Potencial de fosfitos na indução da resistência em plantas de soja. Cultura Agronômica: Revista de Ciências Agronômicas, v.27, n.3, p.263-273, $2018 . \quad$ Disponível em: <http://ojs.unesp.br/index.php/rculturaagronomica/article/view/2569/2028>.

CAIXETA, A. O.; VIEIRA, B. S.; CANEDO, E. J. Efeito do fosfito de potássio sobre fungos fitopatogênicos do feijoeiro. Cerrado Agrociências, v.3, p.35-43, 2012. Disponível $<$ http://revistaagrociencias.unipam.edu.br/documents/57126/58776/efeitofosfito.pdf>.

CONAB. Companhia Nacional de Abastecimento. Acompanhamento da safra brasileira de grãos. 2018. Disponível em: https://www.conab.gov.br/infoagro/safras/graos. Acesso em: 01 out. 2018.

DAMBROS, D.; MONTEIRO, A. L. R.; MELO, A. P.; LINS, S. R. O.; OLIVEIRA, S. M. A. Caracterização epidemiológica e fosfitos no manejo da podridão por Aspergillus niger em uva de mesa. Agrária - Revista Brasileira de Ciências Agrárias, v.11, n.3, p.171-177, 2016. Disponível em: <http://www.agraria.pro.br/ojs2.4.6/index.php?journal=agraria\&page $=$ article $\& o p=v i e w \&$ path\%5B\%5D=agraria_v11i 3a5374\&path\%5B\%5D=4909> . doi: 10.5039/agraria.v11i3a5374.

FERREIRA, D. F. Sisvar: a computer statistical analysis system. Ciência e Agrotecnologia, v.35, p.1039-1042, 2011. Disponível em: < http://www.scielo.br/scielo.php?script=sci_arttext\&pid=S1413-70542011000600001>. doi: $10.1590 / S 1413-70542011000600001$

GODOY, C. V.; ALMEIDA, A. M. R.; COSTAMILAN, L. M.; MEYER, M. C.; DIAS, W. P. et al. Doenças da soja. In: AMORIM, L.; REZENDE, J. A. M.; BERGAMIN FILHO, A.; CAMARGO, L. E. A. Manual de Fitopatologia - Volume 2 - Doenças das Plantas Cultivadas (5 Ed.).. Ouro Fino: Agronômica Ceres Ltda, 2016.

GARCIA, R. Á.; JULIATTI, F. C.; CASSEMIRO, T. A. Produção de escleródios de Sclerotinia sclerotiorum (Lib.) de Bary em meio de cultura. Bioscience Journal, 
v.28, n.1, p.1-7, $2012 . \quad$ Disponível em: <http://www.seer.ufu.br/index.php/biosciencejournal/article/view/8173>.

JULIATTI, F. C.; FIGUEIRÓ, A. A.; GARCIA, R. Á.; SANTOS, J. B.; MACHADO, J. C. et al. Sclerotinia sclerotiorum e mofo branco: estudos básicos e aplicados. Revisão Anual de Patologia de Plantas, v. 23, p. 159-194, 2015. Disponível em: $<$ file:///D:/Downloads/Revisomofobranco11062015.pdf>.

LUCERO, G.; BOITEUX, J.; PIZZUOLO , P.; HAPON, M. V. Effect of copper, zinc and potassium phosphites on the mycelium growth of Phytophthora nicotianae in olive tree dry branch disease. Acta Horticulturae, v.1057, p.437-442, 2014. Disponível em: <https://www.actahort.org/books/1057/1057_55.htm>. doi: 10.17660/ActaHortic.2014.1057.55.

MAIA, F.G.M.; ARMESTO, C.; ZANCAN, W. L. A.; MAIA, J. B.; ABREU, M. S. de. Efeito da temperatura no crescimento micelial, produção e germinação de conídios de Colletotrichum spp. isolados de mangueira com sintomas de antracnose. Bioscience Journal, v. 27, n. 2, p. 205-210. 2011. Disponível em: <http://www.seer.ufu.br/index.php/biosciencejournal/article/view/7581>.

MARCUZZO, L. L.; SCHULLER, A. Sobrevivência e viabilidade de escleródios de Sclerotium rolfsii no solo. Summa Phytopathologica, v. 40, n. 3, p. 281-283, 2014. Disponível em: <http://www.scielo.br/pdf/sp/v40n3/a12v40n3.pdf>. doi: 10.1590/0100-5405/1951.

SUMIDA, C. H.; CANTERI, M. G.; PEITL, D. C.; TIBOLLA, F.; ORSINI, I. P. et al. Chemical and biological control of Sclerotinia stem rot in the soybean crop. Ciência Rural, v.45, n.5, p.760-766, $2015 . \quad$ Disponível em: <http://www.scielo.br/scielo.php?script=sci_arttext\&pid=S0103-

84782015000500760 >. doi: 10.1590/0103-8478cr20140198.

ZAMBOLIM, L.; JESUS JÚNIOR, W. C.; RODRIGUES, F. A. O Essencial da Fitopatologia - Controle de doenças de planta. Viçosa: UFV, 2014.

\section{ANEXO 1}

A fórmula para o cálculo do Índice de Velocidade de Crescimento Micelial (IVCM) é dada por:

IVCM $=\sum(\mathrm{D}-\mathrm{Da}) / \mathrm{N}$

Sendo:

IVCM = índice de velocidade de crescimento micelial

$\mathrm{D}$ = diâmetro médio atual da colônia

$\mathrm{Da}=$ diâmetro médio da colônia do dia anterior

$\mathrm{N}=$ número de dias após a inoculação

A fórmula para o cálculo do \% de Redução do Índice de Velocidade de Crescimento Micelial.

é dada por:

$\%$ redução $=100-(\mathrm{CM} \times 100 / \mathrm{T})$

Sendo:

$\%$ redução $=$ \% de reduçãodo índice de velocidade de crescimento micelial

$\mathrm{CM}=$ diâmetro da colônia

$\mathrm{T}$ = diâmetro da colônia da testemunha 